Available online at

http://www.anpad.org.br/bar

BAR, Curitiba, v. 6, n. 2, art. 2,

p. 101-117, Apr./June 2009

\title{
Brand Equity Evolution: a System Dynamics Model
}

\author{
Edson Crescitelli * \\ E-mail address: edsonc@usp.br \\ Universidade de São Paulo - USP \\ São Paulo, SP, Brazil.
}

\section{Júlio Bastos Figueiredo}

E-mail address: jfigueiredo@espm.br

Escola Superior de Propaganda e Marketing - ESPM

São Paulo, SP, Brazil.

\section{ABSTRACT}

One of the greatest challenges in brand management lies in monitoring brand equity over time. This paper aims to present a simulation model able to represent this evolution. The model was drawn on brand equity concepts developed by Aaker and Joachimsthaler (2000), using the system dynamics methodology. The use of computational dynamic models aims to create new sources of information able to sensitize academics and managers alike to the dynamic implications of their brand management. As a result, an easily implementable model was generated, capable of executing continuous scenario simulations by surveying casual relations among the variables that explain brand equity. Moreover, the existence of a number of system modeling tools will allow extensive application of the concepts used in this study in practical situations, both in professional and educational settings.

Key words: brand equity; system dynamics; modeling; simulation.

Received 26 January 2008; received in revised form 22 October 2008.

Copyright (C) 2009 Brazilian Administration Review. All rights reserved, including rights for translation. Parts of this work may be quoted without prior knowledge on the condition that the source is identified.

* Corresponding author: Edson Crescitelli

Av. Prof. Luciano Gualberto, 903, São Paulo, SP, 05508-900, Brazil. 


\section{INTRODUCTION}

A broad consensus exists among scholars and professionals about the importance of brand in the current competition scenario. Brand has increasingly become the primary battleground in determining a firm's success, regardless of its size or industry. The current marketplace is characterized by strong competition, globalization, ongoing technological advances, fast access to new technologies and consumer demand (Ries \& Ries, 2004).

Having strong brands-i.e., ones that are well-known, have market recognition and add value to a product-is a paramount success factor for most firms (Shimp, 1999). Hence there arises the question of how to build strong brands-in other words, how to generate brand value, or, as referred to herein, brand equity. Though the topic of brand equity (Montgomery \& Lieberman, 2005) can be focused on from several perspectives, this study will address the brand equity building process, excluding the issue of the financial measurement of a brand's value.

There is a series of propositions of brand equity building, which include Keller's model of brand resonance (2001), Millward Brown/WPP's Brandz, and Young and Rubican's BAV (brand asset valuator). This study has opted to follow the model proposed by Aaker and Joachimsthaler (2000), due to its simplicity and general acceptance, despite the fact that it indicates only the factors that form brand equity without mentioning the possible interrelations among these constituent elements or their evolution over time. This study aims to present a simulation model able to represent brand equity development over time, taking into consideration the interaction of its elements.

The research has two basic objectives: (1) to develop a systemic model of the factors determining brand value over time, and (2) to simulate this model. The expected outcome of the research is to provide a differentiated approach to the brand equity building process, thereby contributing to the body of knowledge about this topic.

Given the nature of the proposition, this study should be seen as an exploratory essay, as it only entails a literature review of the topics approached, making no use of empirical research (Severino, 2000). The paper is structured in two sections. The first part presents the foundations of brand equity and system dynamics. The second part looks at the proposed model, discussing each of its components and their interrelations. Finally, the results of the simulations are presented.

\section{LITERATURE REVIEW}

\section{Brand Value}

The importance of brand value is emphasized by Schultz (2001, p. 8) when he says, "The brand promise or value proposition is not a slogan, an icon, a color or a graphic element, even though all those aspects may contribute. On the contrary, it is the heart and soul of the brand". Brand can be currently understood as a set of attributes such as personality, values, associations and quality, which influence the consumer buying process: "Ultimately, a brand is something that resides in the mind of the consumer. It is a perceptive entity rooted in reality, but also more than that, insofar as it reflects consumers' perceptions and idiosyncrasies" (Keller \& Machado, 2006, p. 10).

Brand equity can be discussed from the point of view of investors, manufacturers, resellers and consumers. Each of these groups has a different view about what brand equity means to them. Brands add value to each of these groups in a different way. Investors are driven by financial motivation. Manufacturers and resellers, on the other hand, are more driven by strategic implications (Keller, 2003; Kotler \& Keller, 2006). For the former, brand equity creates a differential advantage that allows 
the firm to generate greater volume and margins. Brand equity provides a platform for introducing new products or to expand an existing product line. For retailers, brand equity contributes to improving the overall image of retail. However, none of these features is relevant if the brand is meaningless to consumers (Crimmins, 1992; Farquhar, 1989). Therefore, it is important to understand how the brand's value is created and sustained in the minds of consumers and how it translates into purchase and consumption behavior.

The concepts of brand are branding and brand equity. Brand is defined by the American Marketing Association [AMA] as "a name, term, design, symbol, a combination of these, or any other feature that identifies one seller's good or service as distinct from those of other sellers" (Pinho, 1996, p. 14). In other words, brand is the final object that concentrates and materializes the other efforts of the brand management process. Branding can be considered as the act of generating brand equity, i.e., as the process of managing (creating and sustaining) brand value (Martins, 2000; Sampaio, 2002). Brand equity has to do with brand value, the brand's strength in its broadest sense, beyond its financial interpretation. Aaker and Joachimsthaler (2000, p. 31) define brand equity as "a set of brand assets and liabilities linked to a brand, its name and symbol, which adds to or subtracts from the value provided by a product or service to a firm". Thus, it is possible to consider branding as the brand management process that will generate brand equity, which will, in turn, make the brand more valuable, maximizing its effect in the market competition process. In fact, these three concepts complement one another (Figure 1) and are not synonymous, as often assumed. According to Aaker and Joachimsthaler (2000, p. 31), "this asset (brand equity) can be understood as the result of four dimensions, namely: brand awareness, perceived quality, brand associations and brand loyalty", as seen in Figure 2.

\section{Figure 1: Relation between Brand, Brand Equity and Branding}

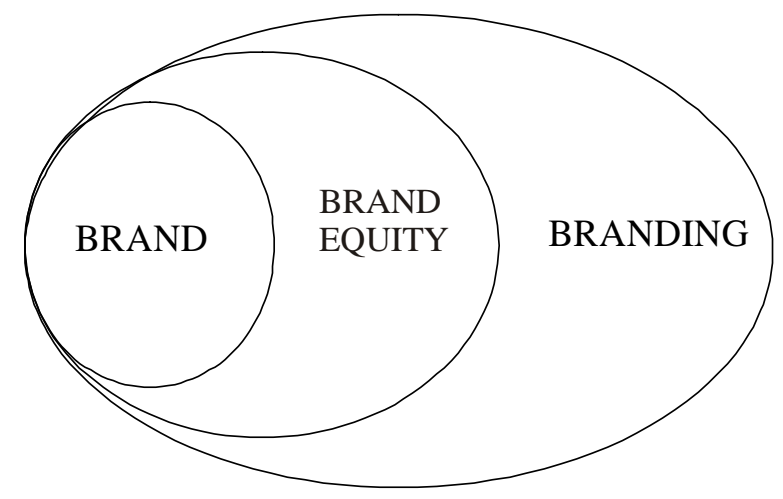

Source: model proposed by the authors.

Figure 2: Brand Equity Dimensions

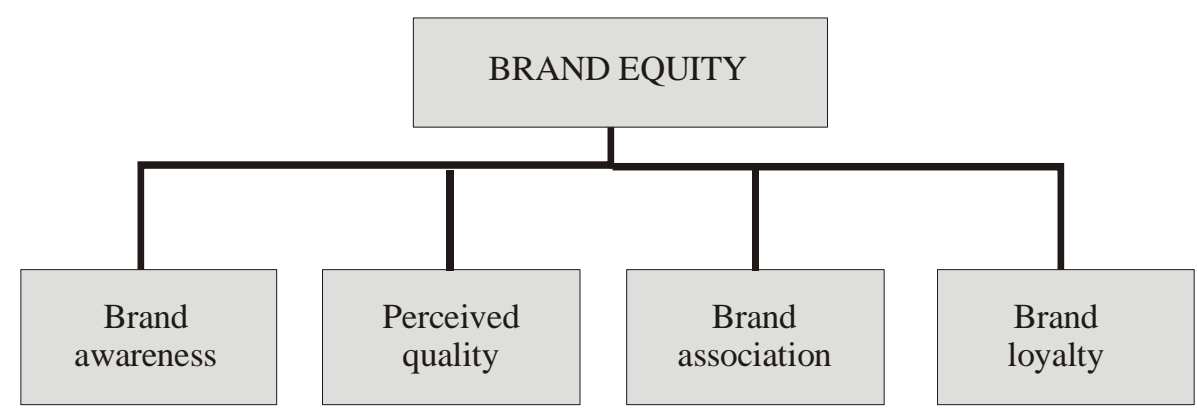

Source: Aaker and Joachimsthaler (2000, p. 31).

In the proposed model, brand awareness refers to the presence of a brand in the minds of consumers. The relevance of the memory of the brand is reinforced by Kapferer (2003, p. 45), who states that: "a 
brand only manifests itself through its actions (models, products, communication, network, etc.). The perceived quality is in the essence of what consumers are buying. For this reason, it is directly correlated with a brand's identity. Nevertheless, the perceived quality can differ from the real quality. Therefore, the creation of a quality product or service is still only a partial victory since it is still necessary to create perceptions of this quality with the market. On the other hand, brand association represents that which a firm wants the brand to represent in the minds of consumers. It is possible to refer to this as brand positioning.

It is worth noting that this same model sometimes appears with a fifth dimension, identified as "other assets of the firm", which includes factors such as patents, trademarks, the relationship with distribution channels, etc. (Aaker, 1998, p. 16). However, this study has opted for the fourdimensional model because it has been adopted by this author in a later work, and also because it better suits the proposed study.

Brand, which is more precisely represented by brand equity, is usually a key strategic resource either to sustain (or weaken) competitive positions, or to value (or devalue) the firm. Penrose (1959) and Barney (1991) basically list two categories of strategic resources: tangible and intangible. Tangible resources are the firm's visible assets, including properties, installations and raw material inventories, among others. Typically, because these can be bought, they add little to competitive advantage, insofar as they can be quickly copied.

\section{System Modeling}

\section{Mental Models}

The planning process that includes the use of simulations departs from decision makers' mental models (Senge, 1990). Such models seek to bring to light the underlying structures of the organizational or social systems being analyzed. In practical cases, the formulation and the work with mental models assume the use of tools for cognitive mapping (Eden, 1988; Pidd, 1996).

An important tool for cognitive mapping is the so-called causal map. These are used to relate two or more entities of a system in order to determine the inter-relatedness between factors. In other words, a connection is said to be causal whenever the occurrence of a first event is a necessary condition for the occurrence of a second event. In a causal map, the arrows that link each variable indicate places where a cause and effect relationship exists. The directional arrows indicate the flow of the relationship. More specifically, the variable at the tail of each arrow can cause a change in the variable at the head of each arrow in the same direction (in the case of a plus sign), and in the opposite direction (in the case of a minus sign).

An effectively practical and functional performance of causal analyses presupposes the use of computational modeling and simulation (Fahey \& Randall, 1998; Forrester, 1961; Roberts, Andersen, Deal, Garet, \& Shaffer, 1983; Sterman, 2000). This permits an assessment of the effects of the alterations on the internal and external variables affecting a firm's strategic situation. Experimenting with alternatives and following them through the visualization of the behavior of those variables becomes thereby possible. The models created allow for the defining of several scenarios and for testing their impact on the system's behavior (Fahey \& Randall, 1998).

\section{Formal Models: System Dynamics}

System Dynamics is a methodology aimed at studying the structures of social or organizational systems by representing the causal relationships among their elements and the evolution of a system over time. Its objective is to elucidate the general behavior of a given system, based on behavior patterns among its parts and on the structures determining those patterns (Forrester, 1961; Pidd, 1996; Roberts et al., 1983; Sterman, 2000). 
The basic idea in system dynamics is that a system's dynamic behavior obeys a principle called the accumulation principle. This principle states that a system's dynamic response derives from the transition of the resources accumulated in stocks and that those transitions are controlled by entry and exit flows of resources in and out of the stocks. This principle leads to a specific causal representation known as stock-and-flow diagrams (Sterman, 2000).

In these diagrams, the stocks (or resources) are graphically represented by rectangular-shaped icons or boxes, in which some resource of the system is accumulated. Stocks are variable and their value (or state) depends on the flows. Flows are represented by arrows with a double trace cut by a triangle. Flows are mechanisms that move the resources within the system. Flows are measures of ongoing processes controlled by equations, and for that reason are represented by icons resembling pipe and faucet assemblies that fill or drain the stocks. Figure 3 shows the basic representation of a stock controlled by a flow in system dynamics (the cloud at the tail of one of the arrows represents a flow source).

Figure 3: Stock $(B)$ Controlled by a Flow $(F)$

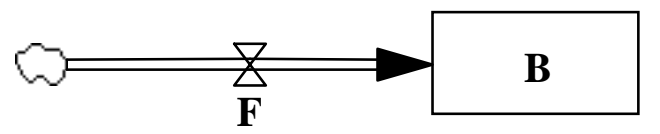

Source: Figueiredo (2005, p. 6).

In Figure 3, the value of the stock $B$ is controlled by flow $F$. This control can be expressed by an equation representing the transition from the value of $B$ from time $t$ to time $t+d t$. This transition is given by the Equation 1:

$$
B(t+d t)=B(t)+F(t) \cdot d t \Rightarrow F(t)=\frac{d B}{d t}
$$

\section{BRAND EQUITY AND SYSTEM DYNAMICS}

The first step in the analysis proposed was to represent the dimensions of brand equity, as proposed by Aaker and Joachimsthaler (2000) and shown in Figure 2, in a system-dynamic model. The result is presented in Figure 4, which is based on the proposal made by Otto (2001), who considered brand equity as the average of four dimensions, herein seen as brand resources: brand awareness, brand association, perceived quality and brand loyalty. Otto pioneered research on this topic, the results of which were also used as a reference for this study.

In the model proposed by Aaker and Joachimsthaler (2000), the four resources appear as independent components of brand equity. The authors do not mention whether they are related and/or in what way. However, based on the premise that those dimensions are interconnected, it is possible to have an understanding that these dimensions are part of a system in which each part simultaneously influences and is influenced by another.

The major part of the elements comprising the proposed model was based on disseminated concepts. Nevertheless, this has not always been possible and, in such cases, this study opted for use concepts based on the theoretical and practical knowledge of its authors. 


\section{Figure 4: Systemic View of Brand Equity Model}

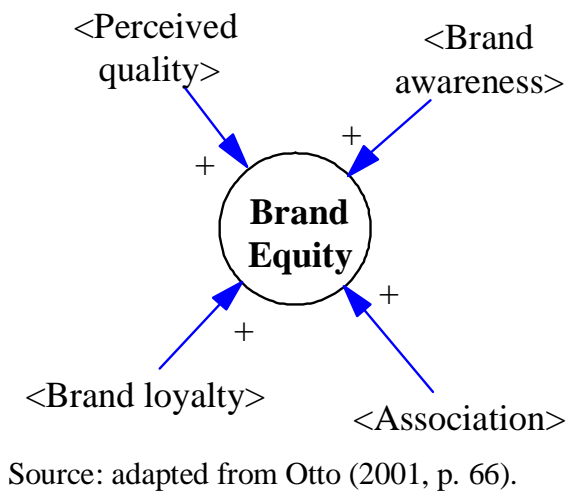

Before presenting the mental model proposed, a few assumptions must be made in order to simplify the modeling process:

i) The brand is still being consolidated, i.e., a brand that is not 'mature' yet;

ii) There is only one rival brand of equal potential and from a company of the same size;

iii) Investments in communications for both brands are equivalent;

iv) The market positioning desired by both brands is similar;

v) Brand awareness, brand associations, perceived quality and brand loyalty are resources that accumulate over time.

This concern is substantiated in Figure 5, which represents the variables and the causal relationships determining the formation of the four key resources that make up brand equity and how they can be understood based on a systemic model.

The resources brand awareness and brand association present direct and indirect gains generated practically from the same sources. Whereas investments in communication yield gains, the natural forgetting rate and competitors' investments in communication generate losses.

Perceived quality represents gains and losses generated by a wide array of factors. This resource stands out in the system, as it is the center upon which several factors converge. It is an essential resource, inasmuch as its contribution to brand equity building influences several other factors. Brand loyalty appears as a resource which predominantly works as a receptacle for the impact of the other variables, mainly that of satisfaction. The mental model that is built allows the development of a simulation model in which the flows feeding the key resources of brand equity will be modeled.

\section{SIGMOIDAL OPERATORS}

In his book on causal analysis, Heise (1975) formalized causal diagramming through simplified algebraic analyses. In Heise's original formulation, causal operators are treated as linear operators. A causal arrow directed from a variable $A$ to a variable $B$ would express a linear function (or linear transformation) of $A$, i.e.:

$$
A \stackrel{\alpha}{\longrightarrow} B \equiv B=\alpha \cdot A
$$


If the right side of the equivalence above is differentiated $d B=\alpha \cdot d A$ is obtained. This means that a variation in $A$ will automatically result in a variation in $B$, scaled by the coefficient $\alpha$. Depending on whether $\alpha$ is a coefficient smaller or larger than the unit, the alteration in $B$ will be relatively bigger than that in $A$. The sign of $\alpha$ also indicates whether the alteration caused in $B$ is positively correlated to the alteration in A, or negatively correlated. Simultaneous causal relations are seen by Heise in an additive way, i.e.:

$$
A \stackrel{\alpha}{\longrightarrow} B \stackrel{\beta}{\longleftarrow} C \equiv B=\alpha \cdot A+\beta \cdot C
$$

It is worth noting that Heise's causal formulation (Equation 2) takes us to the following transitive relation:

$$
A \stackrel{\alpha}{\longrightarrow} B \stackrel{\beta}{\longrightarrow} C \equiv C=\alpha \cdot \beta \cdot A
$$

\section{Figure 5: Mental Model of Brand Equity}

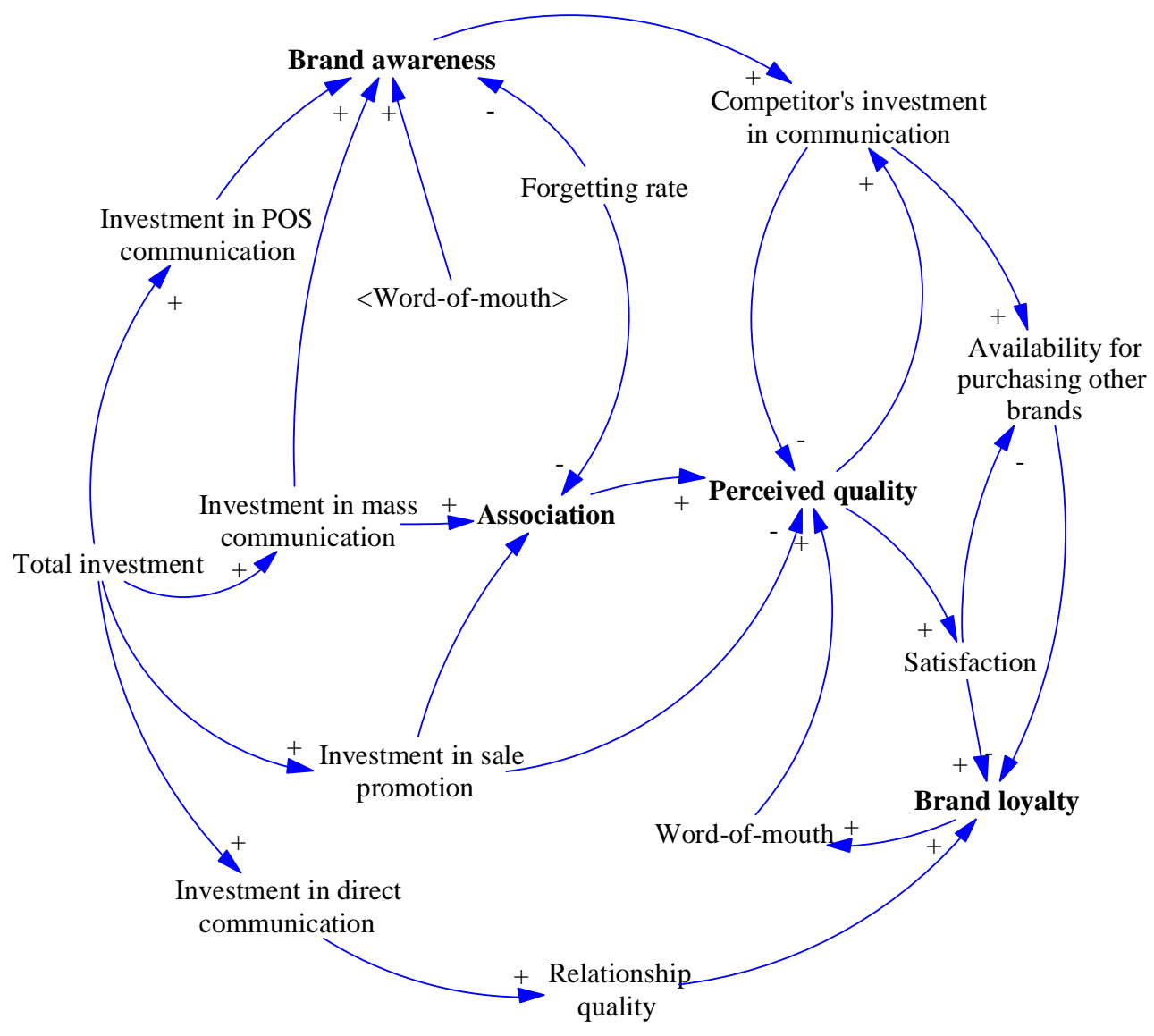

Source: created by the authors.

The equivalence above states that an alteration in $A$ will automatically generate an alteration in $C$ as a consequence of an alteration in $B$. The direct causal relations between variables $A$ and $B$, and between $B$ and $C$, generate a causal relation between $A$ and $C$.

This study followed Heise's structure (1975) for causal relations. However, rather than being considered as strictly linear functions, the operators were considered as sigmoidal functions. The use of sigmoid curves as transfer curves between variables in social systems is related to the economic concept of decreasing scale gains. According to this concept, the performance and productivity of technologies and investments increase almost exponentially in the beginning of the operations, to later 
assuage due to the existence of an increasingly smaller number of targets that can be impacted by their effects or by the loss of efficiency to the resources used. Equation 2 is rewritten as:

$$
A \stackrel{(a, b, k)}{\longrightarrow} B \equiv B=y_{a, b, k}(A)
$$

Where

$$
y_{a, b, k}(t)=\frac{a \cdot t+\ln \left[e^{-a \cdot t}-e^{-a(t+b)}+e^{-a \cdot b}\right]+\ln \left[1+10^{-k}\left(e^{a(t-b)}-e^{-a \cdot b}\right)\right]}{\ln (10)}
$$

Function $y_{a, b, k}(t)$ is known as Baranyi's growth model (Baranyi \& Roberts, 1994). This function was chosen in this study as a transfer function in the model's causal relations because it can be reduced, for some sets of parameters, to a linear function, thereby nearing Heise's original formulation when necessary. The parameters $k, a$ and $b$ in Equation 6 represent, respectively, the loading capacity (maximum transfer limit), the growth speed of the sigmoid curve before saturation and the "lag time" for the beginning of the response (Baranyi \& Roberts, 1994).

The causal relation between the stock $A$ and the flow $F$ is a relation of information transmission. Information loops (represented by arrows in a simple trace) connect some elements of the system, making the relations between the same explicit. It is worth observing that information relations, unlike the flows, do not take away or place resources in the stocks. Using the transitivity relation of Heise's formulation (described in Equation 4) it is possible to ignore the flow $F$ and represent the causal relationship between $A$ and $B$. It is possible to write:

$$
A(t) \longrightarrow B(t) \equiv B(t)=y_{a, b, k}(A(t))
$$

Now it is possible to use Heise's additive principle (Equation 3) to extend this concept to a case where multiple stocks appear (Figure 6). For the sake of convenience and simplicity, the causal variables will be treated as values ranging from 0 to 1 .

Figure 6: Causal Relation between Two Stocks (A, B) through a Flow (F)

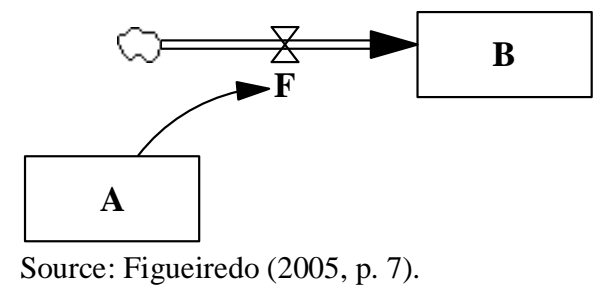

Figure 7 presents a schematic diagram representing the transfer functions between several stocks of percent accumulation. The parameters $a_{i}, b_{i}$ and $k_{i}$ correspond to the parameters in Equation 6 . In Figure 8 , the variables $T_{n}$ are the Baranyi transfer functions (Equation 6). The relationships seen in Figure 8 can be summed up in the equations:

$$
\begin{aligned}
& B(t)=\int_{t_{0}}^{t} F(t) \cdot d t \\
& F(t)=\frac{\sum_{k=1}^{n} T_{k}(t)}{n}
\end{aligned}
$$


Figure 7: Diagram Representing Transfer Functions in Several Stocks

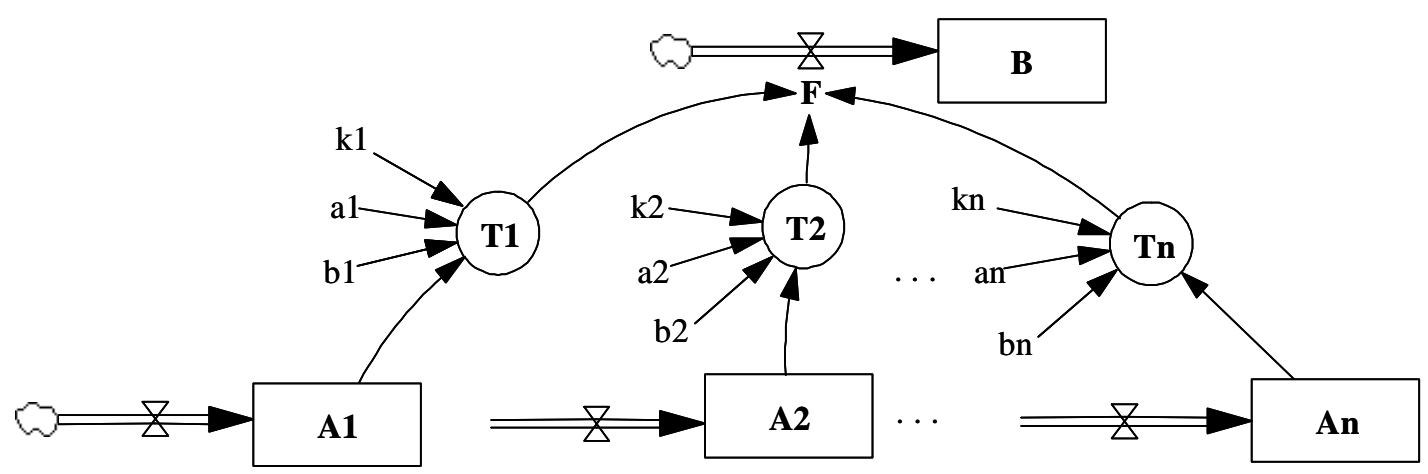

Source: adapted from Figueiredo (2005, p. 8).

\section{SIMULATION RESULTS}

In this article, the models presented were developed through the use of the Vensim Decision Support System software (Ventana, 2004). Figure 8 represents Figure 5's causal diagram using the previously described stock-and-flow approach. It is worth noting that each variable is represented by a stock and that this stock will register the accumulated variation of this variable over time. The flows regulating these stocks depend on the stocks and auxiliary variables that are predecessors in the causal diagram. According to Equation 8, each flow is calculated through the average of the transfer that reaches it.

In the model in Figure 8, the only exogenous variable considered is total investment in communication. This variable depends on a set of investment curves. These curves define the percentages of the total investment that will be spent on mass communication, point-of-sale communication, sales promotion and directed communication. The variables of the exogenous environment are the sources of alteration for the variables of the exogenous environment. The role of scenario modeling is to reveal and make understandable the operational impacts of the external causalities on the internal environment (Georgantzas \& Acar, 1995; Heijden, 1996).

The formats that these investment curves can take over time will define the firm's possible brand equity scenarios. Figure 9 represents investment curves (over 48 months) which, hypothetically, could correspond to three predicted scenarios (summarized in Table 1).

Now it is possible to analyze the system's behavior vis-à-vis these external scenarios and determine how such behavior will influence the other variables considered critical for brand equity. It is possible to test adjustments in the parameters of the transfer functions in an attempt to minimize the effects of some configurations that threaten the scenario.

In order to do that, it is first necessary to discuss what the values of the parameters are for all the transfer curves. Figure 10 shows an example of the panels used to discuss and test these values. 
Figure 8: Stock-and-Flow Diagram of the Mental Model of Figure 5

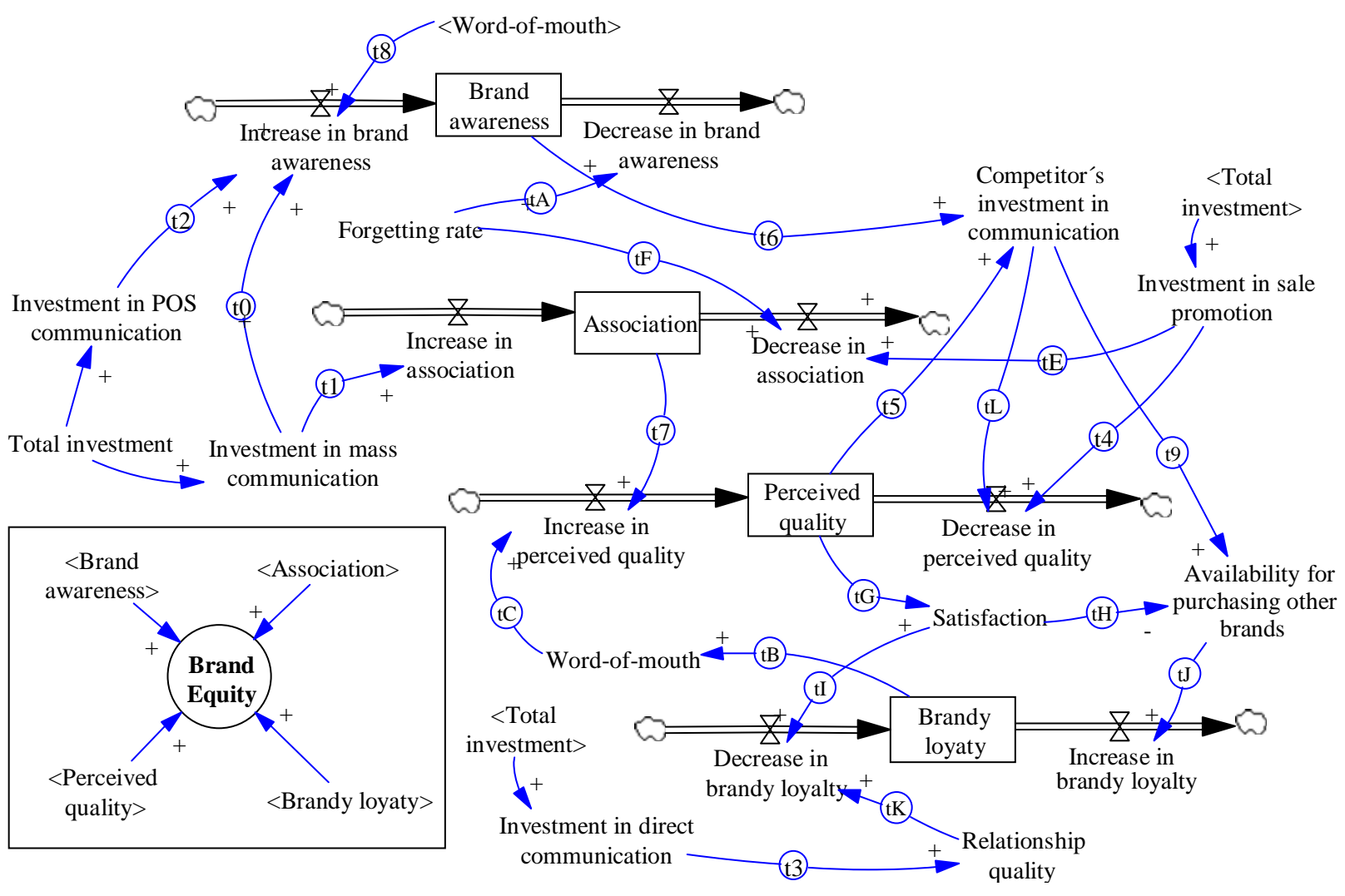

Source: created by the authors.

Table 1: Scenarios for Distribution of Total Investiments

\begin{tabular}{|c|c|c|c|}
\hline & Scenario A & Scenario B & Scenario C \\
\hline Mass communication & $80 \%-60 \%$ & $60 \%-40 \%$ & $40 \%-20 \%$ \\
\hline Directed communication & $0 \%-15 \%$ & $5 \%-25 \%$ & $45 \%-60 \%$ \\
\hline Sales promotion & $0 \%-10 \%$ & $0 \%-20 \%$ & $0 \%-20 \%$ \\
\hline POS communication & $20 \%-15 \%$ & $35 \%-15 \%$ & $5 \%-0 \%$ \\
\hline
\end{tabular}

Source: created by the authors. 
Figure 9: Scenarios for Distribution of Total Investments
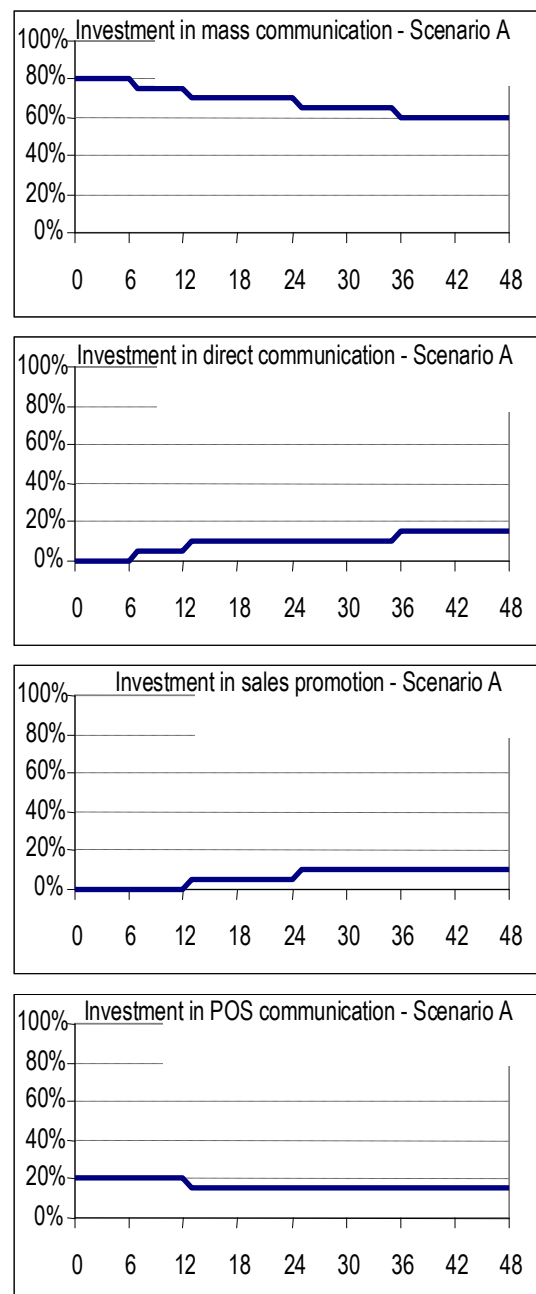

Source: created by the authors.
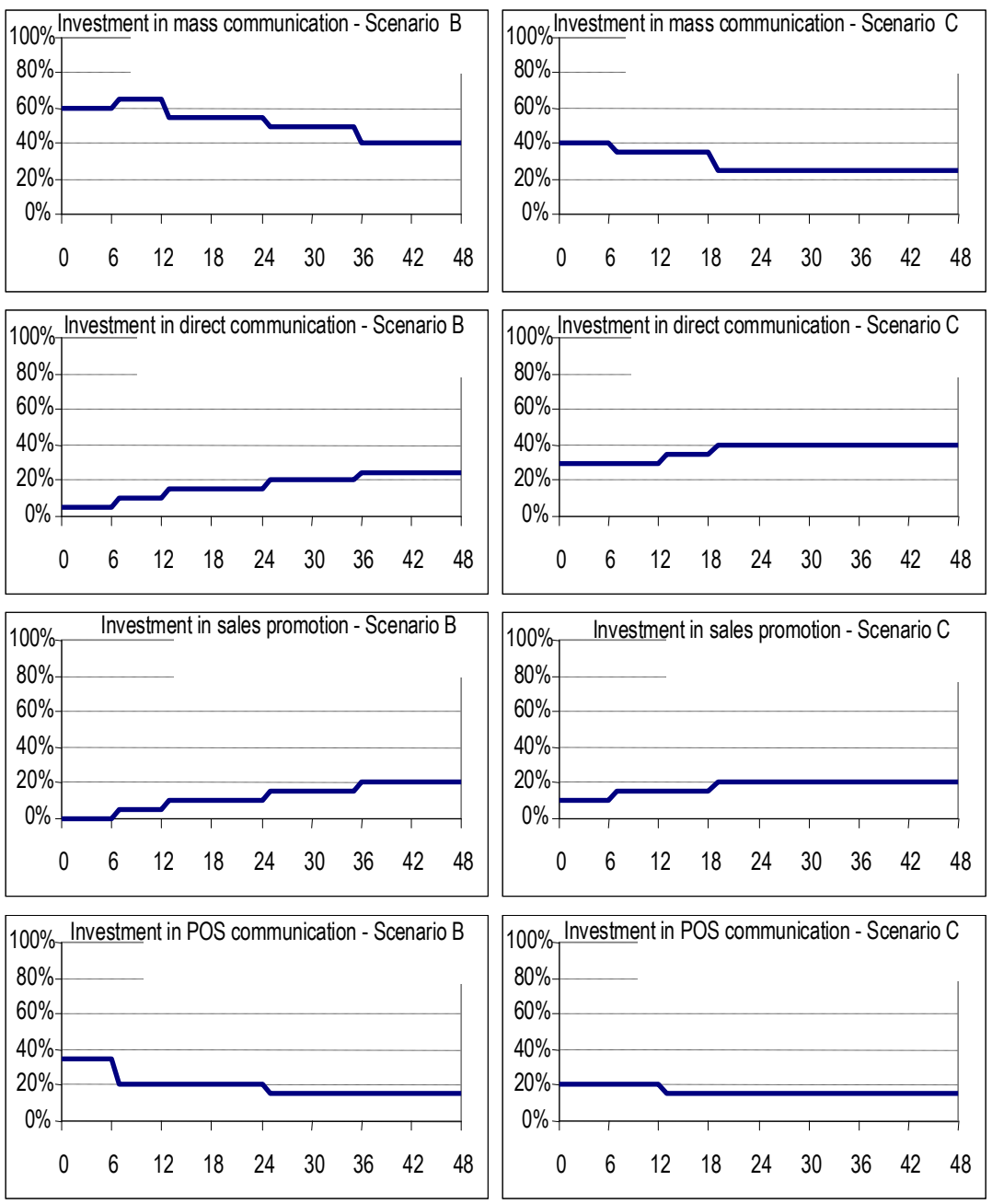

Months

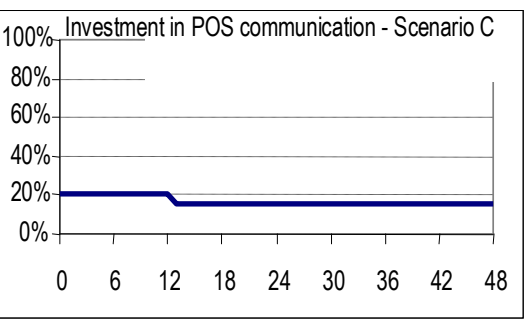

This allows a visualization of the transfer curve of the mass communication investment in gains of awareness. These panels have a set of keys representing each parameter of the transfer functions. These keys can be modified to test their joint effect on the pre-selected variables. The idea is that, by using this type of resource, decision makers can discuss, based on their experiences and the data collected, the most reasonable values for the parameters, confronting them with real-life situations. Simulation environments like the one in Figure 11 can be used if we want to observe the effect of the changes on the parameters in a wider context, taking more variables into consideration In that case, all the implications of the alterations in the parameters can be observed simultaneously on all variables, including on the transfer variables. 
Figure 10: Transfer Curve: Investment in Mass com. $\rightarrow$ Increase in Brand Awareness

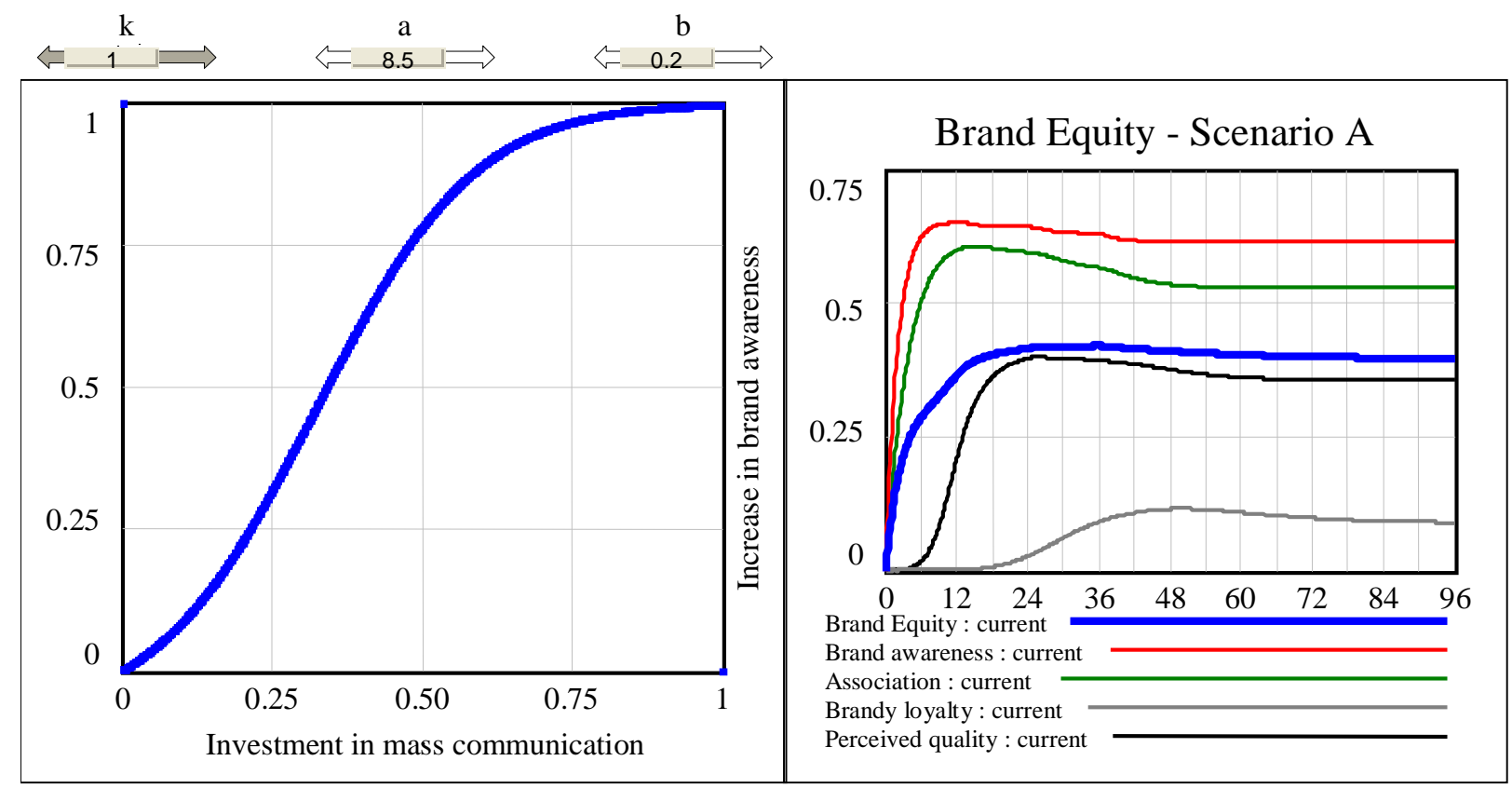

Source: created by the authors.

Let us now consider the set of scenarios seen in Figure 9, which enables the building of a 96 monthsimulation. Results of the simulation are presented in Figures 12 (A), 13 (B) and 14 (C). They clearly show that scenario $\mathrm{C}$ generates a result of brand equity much inferior to those achieved in scenarios $\mathrm{A}$ and B in the 96-month period in question. Despite the fact that the total monthly investments in the three scenarios are the same (0.85), it is easy to explain the result, given that the initial volume of investments in mass communication in scenario $\mathrm{C}$ is lower than that of the others and decreases over time. This fact eventually inhibits the growth of brand awareness and, therefore, the growth of the other resources.

Another example illustrates well the potential of this type of tool for the practical analysis of assumptions in planning situations. Let us suppose that it is not possible to determine with certainty the impact on the possible variations of the forgetting rate on brand loyalty. However, supposing that there is an idea about the ranges of this variation, it is thus possible to build a number of simulations, considering the possible values, which are distributed so as to give an idea of the model's sensibility to those variations. The final result is a graph like the one presented in Figure 15.

In Figure 15, the parameters of earlier simulations were kept for scenario A. The forgetting rate of the market was considered to range between $35 \%$ and $45 \%$ per month. The aim was to assess the impact of this variation on brand loyalty. As a result, a curve is obtained representing, with the respective degree of confidence, the possible scenarios for brand loyalty. 


\section{Figure 11: Overview of the Simulated Model}

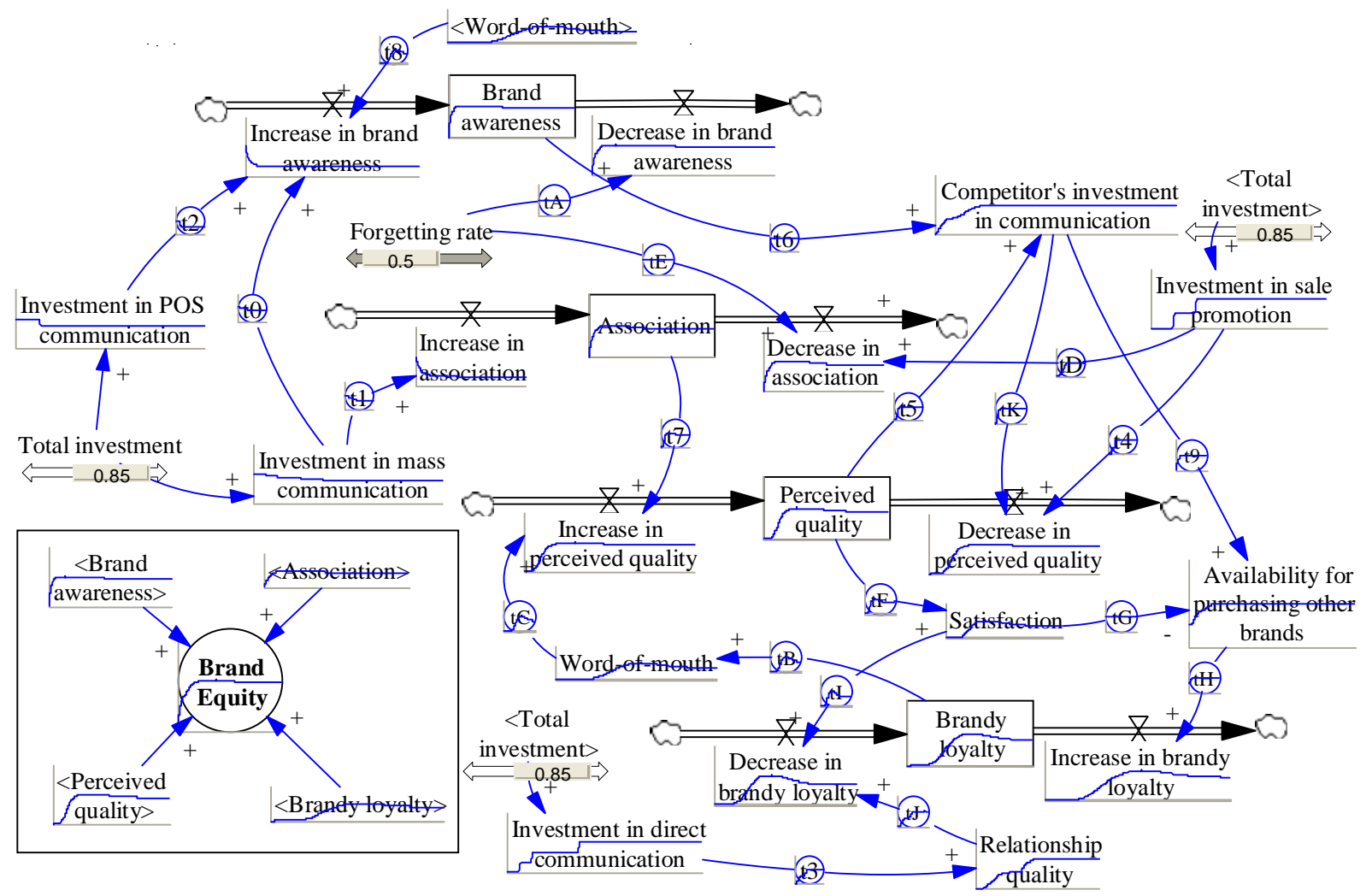

Source: created by the authors.

\section{CONCLUSIONS}

Modeling and simulation techniques have been developed, by and large, as tools to deal with situations able to be mathematically structured and showing a strong propensity for predictability and optimization. However, modeling and simulation can and must be explored as processes for capturing, structuring and understanding our mental models and knowledge. When allied to simple and straightforward mathematical formulations, their vocation as learning tools is enhanced, stimulating us to test the limits of our reality vis-à-vis the models herein conceived.

This type of model allows space and time to be easily compressed in order to catalyze the development of events intended for analysis. Additionally, it is possible to decrease the speed of processes so as to better study them. Inside these so-called micro worlds, it is possible to experience the long-term side-effects of decisions made, as well as systematically explore new strategies. Thus it is possible to develop an understanding about the complexity of the systems with which we work and live.

This study aimed to contribute to offer those working with brand planning - mainly with regard to education, scenario analyses and systemic behavior- a simple, practical model to deal with the complexity that planners come across daily.

The findings and conclusions drawn from this study need to be interpreted with some caution. Simulation models can provide accurate and insightful means to analyze and predict the performance measures of a particular system. However, when simulating and analyzing a complex system such as brand equity, one must be aware of the dangers of using incorrect procedures, which can result in 
erroneous results. The validation of the concepts and relations used to build the system structure addresses some of these issues.

For example, in the case of the brand equity model shown in this article, the assumption for the structure consists of the description and theory from the literature and of theoretical and practical knowledge of its authors. However, simulation models have their principal weak points in regard to the description of their variables, and in the particular choice of the variables' relations (Sterman, 2000). Many challenges in this study remain to have as much as possible a valid representation of the system structure.

Another limitation of this research is that it is based on a single case from one company with only one rival brand of equal potential and from a company of the same size. This is very simple when compared with real markets. Moreover, the brand policies examined in the paper are restricted to the investments in different forms of promotion. Promotion does not operate in isolation when actually implemented in the market. The response to a particular competitive action such as price reduction, changing a marketing strategy, or the distribution policy, is not captured in the model, thus assuming stable and static market conditions, which also is not the case in the real markets.

A further limitation of this research is that the value of the parameters in the sigmoidal equations underlying the brand equity model are somewhat ad hoc; even though they represent the authors' experience, more research is needed on the best specifications of these parameters values.

In its exploratory nature, the project revealed that brand equity analysis, based on the system dynamics approach, allows us to observe that: i) the brand equity process is very complex; ii) a more rational view of brand equity is possible; the financial approach is not the only way to escape the subjectivity involved in brand equity; iii) brand equity is influenced by a number of factors somehow interconnected in brand value building.

Figure 12: 96-Month Simulation Considering Scenario A

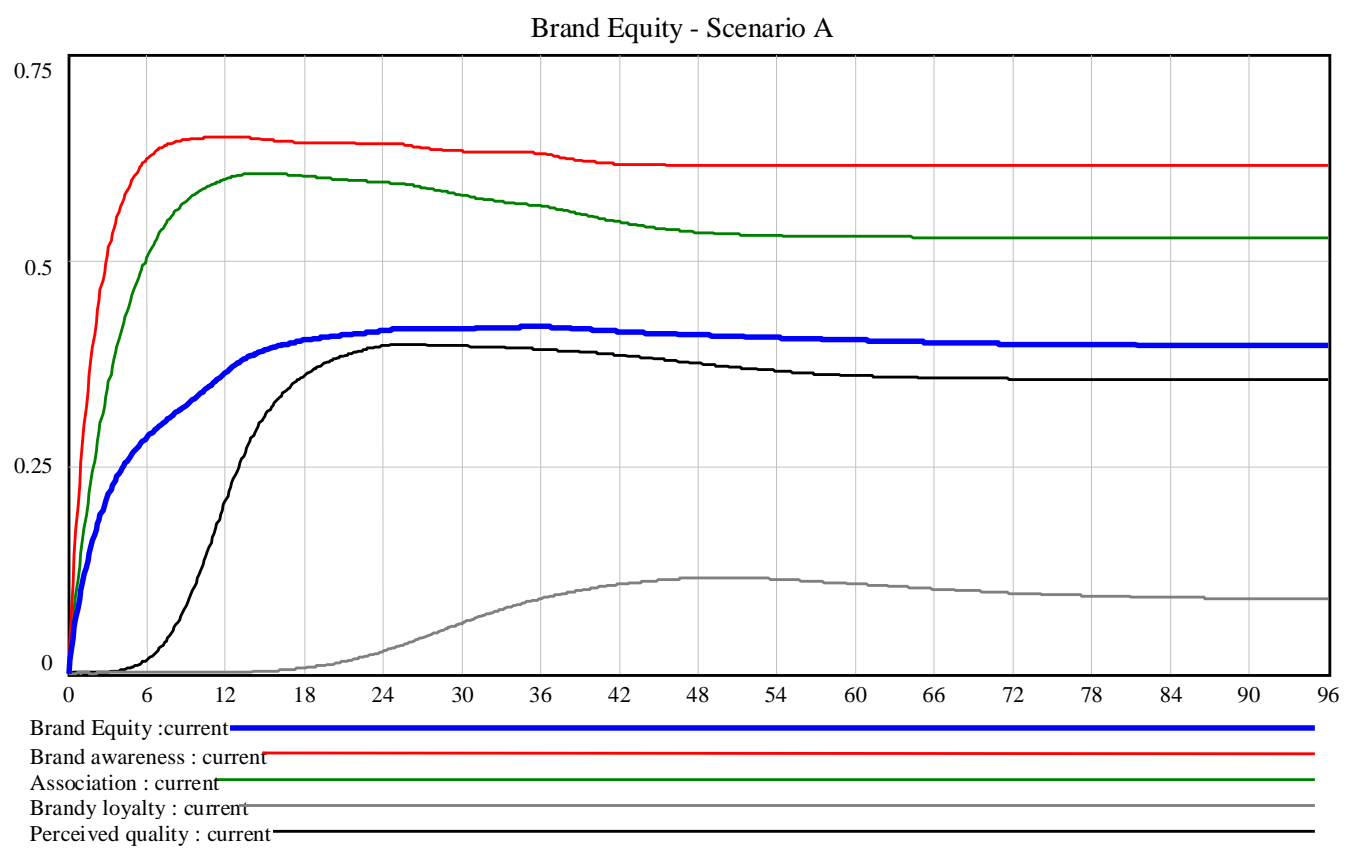

Source: created by the authors. 
Figure 13: 96-Month Simulation Considering Scenario B

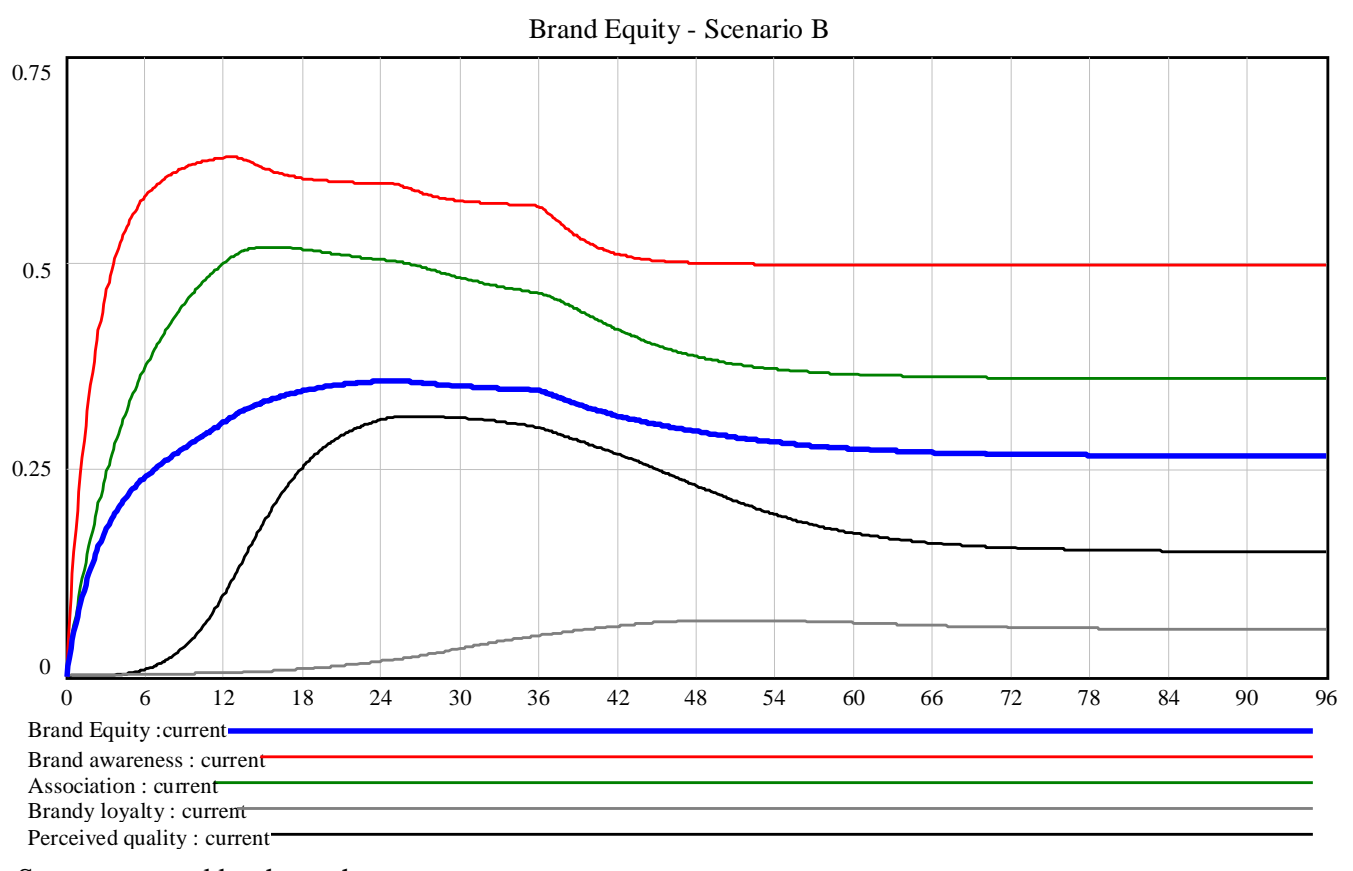

Source: created by the authors.

Figure 14: 96-Month Simulation Considering Scenario C

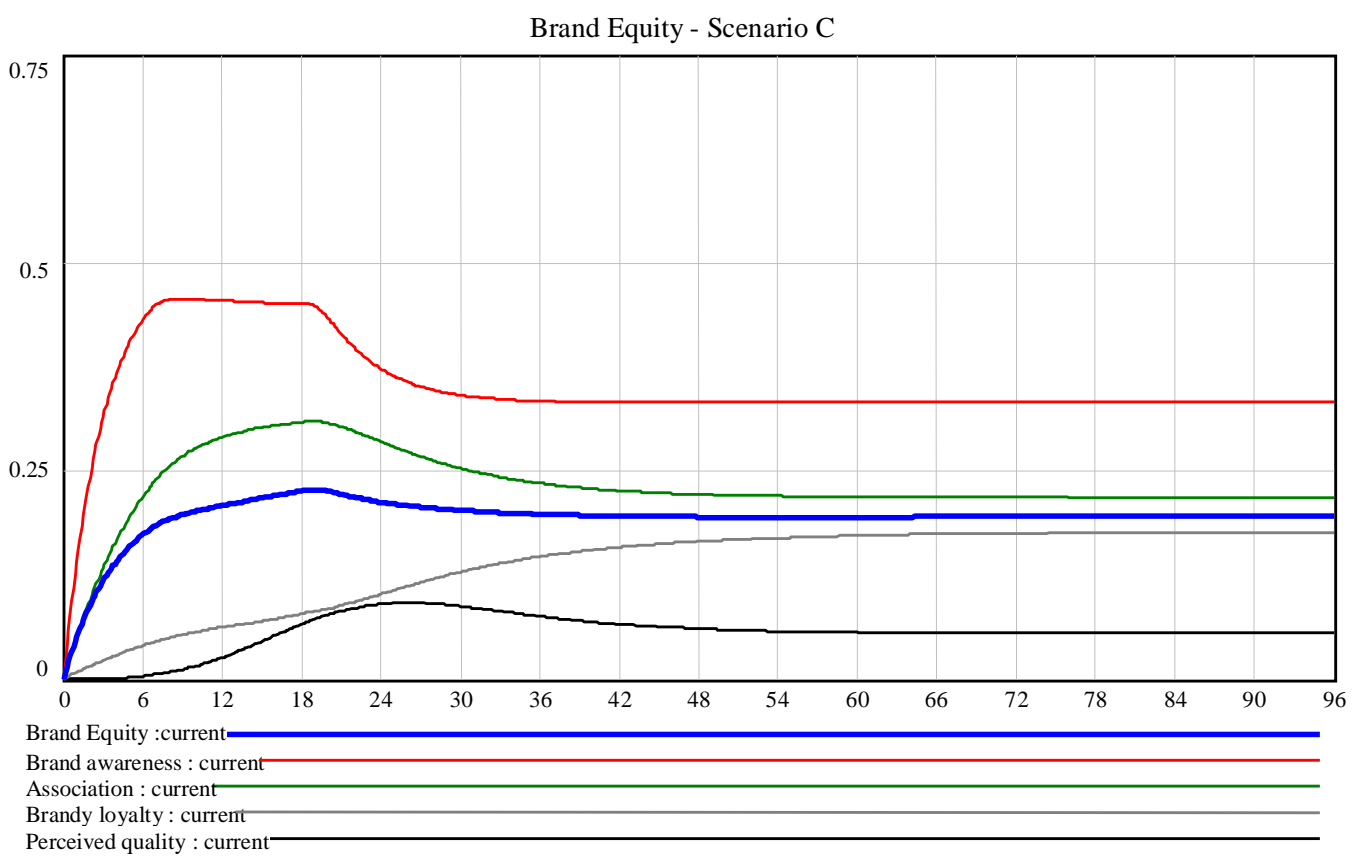

Source: created by the authors. 
Figure 15: Example of Sensibility Analysis

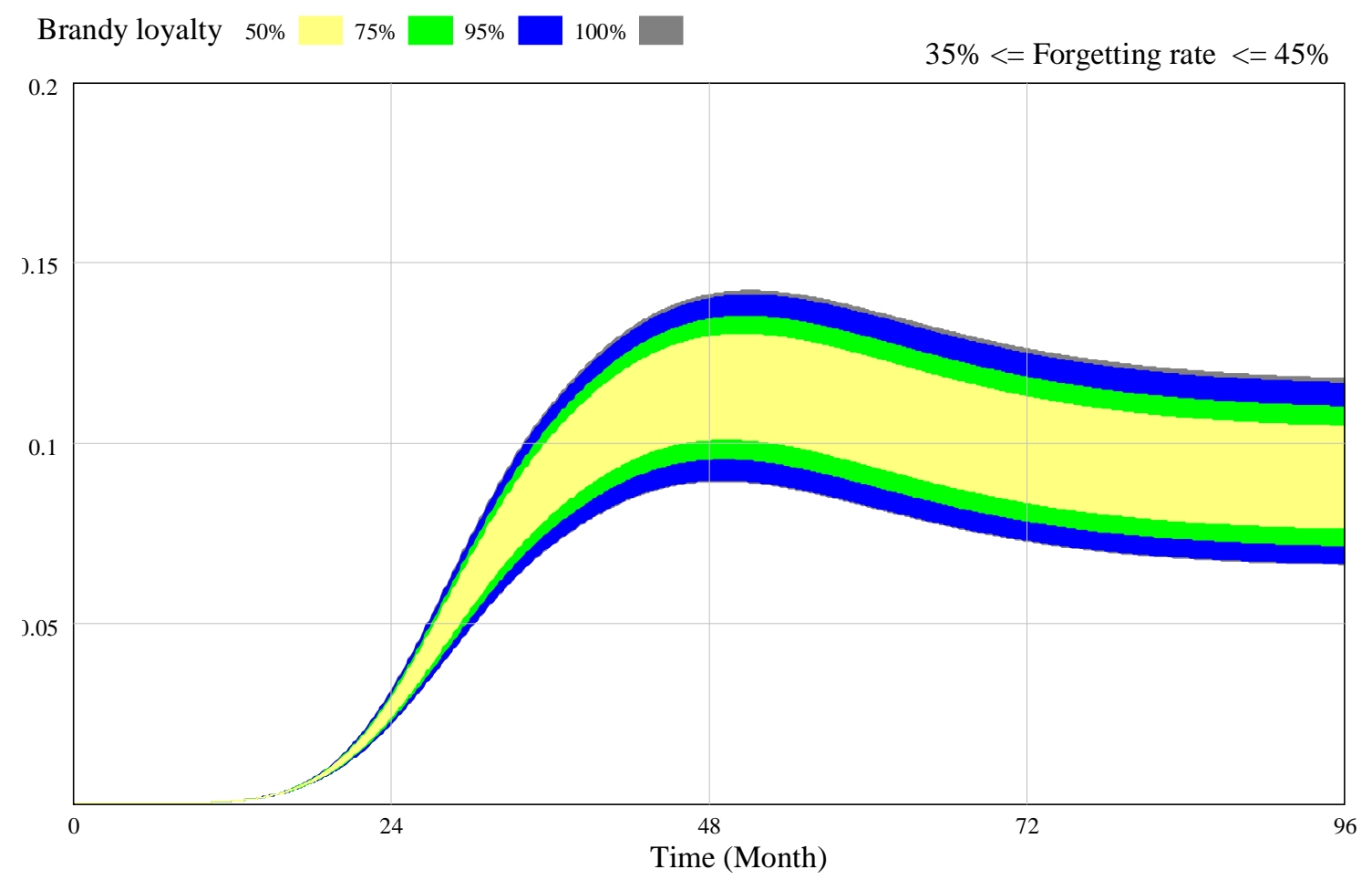

Source: created by the authors.

\section{REFERENCES}

Aaker, D. A. (1998). Managing brand equity. New York: Simon \& Schuster.

Aaker, D. A., \& Joachimsthaler, E. (2000). Brand leardership. New York: The free press.

Baranyi, J., \& Roberts, T. A. (1994). Dynamic approach to predicting bacterial growth in food. International Journal Food Microbiol, 23(1), 277-294.

Barney, J. B. (1991). Firm resources and sustained competitive advantage. Journal of Management, 17(1), 99-120.

Crimmins, J. C. (1992). Better measurement and management of brand value. Journal of Advertising Research, 32, 11-19.

Eden, C. (1988). Cognitive mapping. European Journal of Operational Research, 36(1), 1-13.

Fahey, L., \& Randal, R. M. (1998). Learning from the future. New York: John Wiley \& Sons.

Farquhar, P. H. (1989). Managing brand equity. Marketing Research, 1, 24-33.

Figueiredo, J. C. B. (2005, agosto/ setembro). Uso de operadores causais lineares no desenvolvimento de cenários computacionais em planejamento estratégico. Anais do Simpósio de Administração da Produção, Logística e Operações Internacionais, São Paulo, SP, Brasil, 8.

Forrester, J. W. (1961). Industrial dynamics. Cambridge, MA: MIT Press. 
Georgantzas, N., \& Acar, W. (1995). Scenario-driven planning: learning to manage strategic uncertainty. Westport, CT: Quorum Books.

Heijden, K. van der (1996). Scenarios the art of strategic conversation. New York: Wiley.

Heise, D. R. (1975). Causal analysis. New York: Wiley.

Kapferer, J. N. (1998). Lês marques, capital de l'entreprise. Paris: Éditions d'Organization.

Kapferer, J. N. (2003). As marcas, capital da empresa (3a ed.). Porto Alegre: Bookman.

Keller, K. L. (2001). Building customer-based brand equity: a blueprint for creating strong brands. Marketing Management, 10(2), 15-19.

Keller, K. L. (2003). Strategic brand management: building, measuring, and managing brand equity. Upper Saddle River, NJ: Pearson Education.

Keller, K. L., \& Machado, M. (2006). Marketing management. São Paulo: Prentice Hall.

Kotler, P., \& Keller, K. L. (2006). Marketing management (12th ed.). New York: Prentice Hall.

Martins, J. R. (2000). Branding: um manual para você criar, avaliar e gerenciar marcas. São Paulo: Negócio Editora.

Montgomery, J., \& Lieberman, M. (2005). A compendium of brand measurement. World Advertising Research Center, (464), 45-47.

Otto, P. (2001, July). Brand management facilitation: a system dynamics approach for decision makers. Proceedings of the International System Dynamics Conference. Atlanta, Georgia, USA, 19.

Penrose, E. T. (1959). The theory of the growth of the firm. New York: Wiley.

Pidd, M. (1996). Tools for thinking: modeling in management science. Chichester: Wiley.

Pinho, J. B. (1996). O poder das marcas (2th ed.). São Paulo: Summus.

Ries, A., \& Ries, L. (2004). The origin of brands. New York: Harper Collins Publishers Inc.

Roberts, N., Andersen, D. F., Deal, R. M., Garet, M. S., \& Shaffer, W. A. (1983). Introduction to computer simulation: a system dynamics modeling approach. Reading, MA: Addison-Wesley.

Sampaio, R. (2002). Marcas de A a Z. Como construir marcas como usar a propaganda para construir marcas de sucesso. Rio de Janeiro: Campus.

Schultz, D. E. (2001). Getting to the heart of the brand. Marketing Management, 10(3), 8-9.

Senge, P. M. (1990). The fifth discipline: the art and practice of the learning organization. New York: Doubleday.

Severino, A. J. (2000). Metodologia do trabalho científico (21th ed.). São Paulo: Cortez.

Shimp, T. A. (1999). Advertising \& promotion: supplemental aspects of integrated marketing communications (5th ed.). Orlando: Drydren Press.

Sterman, J. D. (2000). Business dynamics: system thinking and modeling for a complex world. Boston: McGraw-Hill.

Ventana Systems, Inc. (2004). Vensim help manual (Vensim 5.3a.). [Software]. Harvard, MA: Autor. Retrieved April 28, 2006, from http://www.vensim.com/freedownload.html 